\title{
Laser assisted uvulopalatoplasty in sleep disordered breathing
}

\author{
C Francis Ryan
}

Laser assisted uvulopalatoplasty (LAUP) is a new surgical procedure for the treatment of snoring that is modelled on the uvulopalatopharyngoplasty (UPPP) operation for obstructive sleep apnoea (OSA). Since LAUP is technically simple, can be performed under local rather than general anaesthetic, and is carried out in the doctor's surgery, it has received widespread publicity and its use has proliferated throughout Western Europe and North America. The rapid expansion in the use of LAUP has occurred despite a lack of objective evidence regarding the indications, safety, and efficacy of this procedure for the treatment of snoring. Furthermore, LAUP is now being offered as a treatment for OSA. Considering the recognised difficulty in distinguishing between simple snoring and OSA on clinical grounds alone, and the general infrequency with which preoperative sleep monitoring is performed prior to LAUP, it is likely that many patients with undiagnosed OSA are undergoing LAUP for their snoring without due regard for the potential impact of this surgical procedure on their sleep disordered breathing. There are many unanswered questions concerning the role of LAUP in the treatment of snoring and OSA. Until more objective data are available, prudence dictates a cautious approach to this new treatment modality, including complete preoperative diagnosis, adequate postoperative follow up, and advice to patients that LAUP is still an experimental procedure. ${ }^{1}$

Chronic snoring occurs in $20 \%$ of all adults. ${ }^{2}$ Snoring is little more than a trivial nuisance for most people, but its importance as a symptom lies in its potential for social and marital disharmony, its association with increased cardiovascular morbidity, ${ }^{34}$ and its relationship with more serious respiratory sleep disorders such as OSA. Snoring is the most common presenting symptom of OSA. While not all snorers have OSA, virtually every patient with OSA snores. Snoring is a predominantly inspiratory sound arising from the pharynx during sleep. ${ }^{5}$ The noise made by snoring, which can reach levels in excess of 85 decibels, is produced by vibration of the pharyngeal soft tissues (soft palate, tonsillar fauces, posterolateral oropharyngeal walls, and base of the tongue). Snoring is probably caused by an unstable occlusion of the pharyngeal airway which, under circumstances of increased inspiratory airflow resistance, behaves like a Starling resistor. ${ }^{6}$ Any increase in inspiratory airflow resistance due to upper airway narrowing will predispose to snoring and upper airway occlusion during sleep. The similarities between the physiological events during sleep in snorers and patients with OSA, and the fact that OSA is usually preceded by decades of loud snoring, suggest that snoring constitutes the first stage in the natural history of OSA.

Obstructive sleep apnoea is a relatively common condition that affects $1-4 \%$ of the adult population. ${ }^{78} \mathrm{Al}-$ though certain manifestations of this syndrome have been described for many years, a wider recognition of its pathophysiology and clinical features has only occurred in the last decade. ${ }^{9}$ OSA is characterised by snoring and recurrent apnoea during sleep which results in episodic asphyxia and interruption of the normal sleep pattern. In addition to disabling symptoms, patients with OSA may develop significant complications such as systemic hypertension, heart failure, and cardiac arrhythmias. OSA occurs because of recurrent occlusion of the upper airway during sleep. Upper airway occlusion can develop at various locations in the pharynx, but most commonly occurs at the level of the velopharynx, behind the soft palate. ${ }^{10-14}$ Patients with OSA have been shown to have narrower upper airways, particularly at the level of the velopharynx. ${ }^{111516}$ Studies have also indicated a more collapsible velopharynx in patients with OSA. ${ }^{17}$ These abnormalities of size and function render the upper airway more susceptible to occlusion during sleep, in association with the sleep related decline in upper airway dilator muscle activity.

Nasal continuous positive airway pressure (CPAP) is the treatment of choice for patients with OSA who fail to respond to conservative measures. Nasal CPAP works by providing a pneumatic splint for the upper airway, preventing its collapse during sleep. ${ }^{18}$ It is a highly effective treatment for OSA. Unfortunately, because it is inherently cumbersome, up to $30 \%$ of patients are unable to tolerate nasal CPAP therapy on a long term basis and are obliged to consider alternative treatments such as corrective upper airway surgery. In 1964 Ikematsu $^{19}$ first described the uvulopalatopharyngoplasty (UPPP) procedure for the treatment of severe snoring which was subsequently modified for the treatment of OSA by Fujita et al. ${ }^{20}$ The UPPP procedure enlarges the upper airway by removing excess distal palatal tissue while preserving the function of the proximal palatal musculature. The success of this operation varies considerably, and up to $60 \%$ of patients continue to have significant OSA following it. ${ }^{21}$ There are limited objective data regarding the long term efficacy of UPPP or the factors associated with a successful outcome. UPPP requires admission to hospital and general anaesthesia and is associated with significant early postoperative morbidity including pain, haemorrhage, velopharyngeal insufficiency, and nasopharyngeal stenosis. As a result it has not gained widespread acceptance for the treatment of simple snoring.

Laser assisted uvulopalatoplasty is a new surgical technique first introduced by $\mathrm{Kamami}^{22}$ for the treatment of snoring. It is a modification of the UPPP procedure that generally utilises a staged surgical approach and a less radical resection of oropharyngeal tissue. The LAUP procedure is carried out in the doctor's surgery under local anaesthesia using a hand held $\mathrm{CO}_{2}$ laser. A controlled resection of the uvula and soft palate is performed in 1-5 stages at approximately monthly intervals until the desired outcome (elimination of snoring) is achieved. Healing and scar contraction are associated with widening, stiffening, and elevation of the soft palate.

From the perspective of the patient and the otolaryngologist, LAUP offers several potential advantages over other treatment options for snoring and OSA. The inconvenience and expense of a hospital admission, general anaesthetic, and absence from work associated with a UPPP are avoided. In many instances LAUP is now offered as a one stage procedure similar to a UPPP ${ }^{23-25}$ and, as such, may be the cheapest therapeutic option currently available. In British Columbia, for instance, a one stage LAUP for the equivalent of $£ 250$ compares favourably with nasal CPAP therapy for $£ 650$ or an oral appliance for $£ 750$. A successful LAUP may obviate the necessity for long term less convenient therapy such as lifestyle modification, nasal 
CPAP, or an oral appliance. It is claimed that LAUP is associated with less postoperative morbidity than UPPP. These potential advantages have resulted in the promulgation and widespread proliferation of LAUP in the absence of objective data to support its safety and efficacy.

This practice of uncontrolled development of surgical innovations is commonplace and by no means confined to upper airway surgery for snoring and OSA. ${ }^{26}$ Whereas regulatory agencies play a major part in the development of new drugs and devices such as nasal CPAP, surgical procedures are relatively unregulated. Initial testing is usually carried out in an uncontrolled fashion and rarely subjected to the rigours of a randomised controlled trial. ${ }^{27}$ Initial studies tend to suffer from numerous methodological limitations that render it difficult to interpret the results. Such was the case with the literature on UPPP, whose deficiencies were well outlined recently in an extensive review by Schechtman and colleagues. ${ }^{28} \mathrm{~A}$ Medline search identified 87 articles on UPPP, of which only 37 had a sample size of 10 or more and a clear and unambiguous outcome measure. Among the 37 studies several important methodological problems were identified including inadequate statistical power, absence of confidence bounds, uncontrolled design, inadequate follow up, uncertain generalisability, absence of quality of life assessment, multiple end points, missing data, inconsistent definitions, and biased baseline data. The authors concluded that the catalogue of information that remained unknown about UPPP was needlessly large. Upon reviewing the current literature on LAUP it is clear that these methodological problems persist. It is likely therefore that large numbers of patients have undergone, and will continue to undergo, LAUP without the benefit of properly designed clinical trials to determine the potential risks and efficacy of this procedure.

For the reasons already outlined, it is difficult to glean useful information from the 15 or so studies published to date on the use of LAUP for snoring and OSA. ${ }^{22-2529-40}$ Firstly, there is considerable variation in the surgical technique. Most studies report the use of a $\mathrm{CO}_{2}$ laser, but two studies report a similar surgical procedure using electrocautery. ${ }^{3436}$ Six studies describe a technique of vertical transpalatal trench incisions lateral to the uvula combined with subtotal uvulectomy and variable resection of palatal and tonsillar tissue, ${ }^{25} 3132353839$ three studies describe a procedure similar to UPPP, ${ }^{232437}$ while yet another technique called mucosal strip/uvulectomy consisting of a laser burn to a strip of ventral soft palate in conjunction with a partial uvulectomy is also described. ${ }^{3033}$ In many studies additional surgery such as tonsillectomy, nasal turbinectomy, or midline glossectomy was also performed. LAUP may be performed as a single stage resection or as a multi-staged sequential resection of palatal tissue until the desired therapeutic objective (elimination of snoring) is attained. Given this heterogeneity of surgical technique, it is difficult to generalise from the results of individual studies. In most studies patient selection criteria were unclear and preoperative sleep monitoring was not performed. Study end points were not clearly defined and postoperative sleep monitoring was rarely performed. Improvement in snoring was assessed by questionnaire data rather than objective measures. None of the studies used a randomised controlled design, a power calculation for sample size, or an assessment of quality of life using a validated instrument, and no study had follow up beyond six months. Only two studies attempted any statistical analysis $^{3338}$ or reported confidence limits. ${ }^{33}$

Notwithstanding these methodological limitations, certain tentative observations can be made based on the available data. The reported efficacy of LAUP for alleviating snoring varies, with $29 \%$ (range 5-84\%) of patients being cured and 78\% (range 67-95\%) improved. The accuracy of self-reported data on snoring has been questioned, however. Miljeteig and coworkers ${ }^{41}$ analysed questionnaire responses in 100 unselected patients who underwent UPPP. The patients had no improvement in objective measures of apnoea and snoring on polysomnography but had significant subjective improvement in the perception of snoring and quality of sleep by the patient and bed partner. If patient and bed partner satisfaction were the only relevant end points in the treatment of snoring, this discrepancy between subjective and objective outcomes would not matter a great deal. This ignores the fact, however, that snoring is a risk factor for cardiovascular disease and is commonly associated with OSA, a condition with significant morbidity that may not be adequately treated by LAUP. This problem of relevant end points is compounded by the fact that many of the studies relied on patient histories to distinguish between simple snoring and OSA. There is ample evidence that clinical symptoms alone are inadequate to rule out OSA. ${ }^{42-45}$ This issue was specifically addressed by Vaidya and associates ${ }^{40}$ who attempted to develop a predictive model for the diagnosis of OSA based on questionnaires in 309 patients presenting for LAUP but were unable to determine a group of symptoms or patient characteristics that reliably differentiated between apnoeic and nonapnoeic patients.

Only two studies reporting the results of LAUP for the treatment of OSA had sufficient data to allow some assessment of efficacy. Walker and associates ${ }^{35}$ reported 33 patients who had repeat polysomnography $4-6$ weeks after LAUP. The operative technique consisted of vertical transpalatal incisions lateral to the uvula followed by subtotal uvulectomy. OSA was defined as a respiratory disturbance index (RDI) of $>5 /$ hour, yet postoperative success was defined as an RDI of $<10 /$ hour. After LAUP 11 patients $(33 \%)$ had an RDI of $<5 /$ hour, $16(48 \%)$ had an RDI of $<10$ /hour, and $21(64 \%)$ had a $>50 \%$ reduction in RDI, five $(15 \%)$ were unchanged, and seven $(21 \%)$ were worse after LAUP. Mickelson and coworkers ${ }^{37}$ obtained postoperative polysomnograms in 13 patients $6-8$ weeks after LAUP. The operative procedure consisted of a staged resection of the uvula and soft palate under local anaesthesia resulting in a postoperative appearance of the palate similar to UPPP. The mean (SD) apnoea index (AI) decreased from $19(18) /$ hour to $4(3) /$ hour $(\mathrm{p}=0.006)$, the RDI decreased from 31 (21)/hour to 16 (8)/hour (not significant), seven patients $(54 \%)$ had a $>50 \%$ reduction in RDI and five $(38 \%)$ had an RDI of $<10 /$ hour after LAUP, and three patients $(23 \%)$ were worse after the operation. Superficially these results resemble those obtained by UPPP, but it is worth highlighting that in $21-23 \%$ of patients their OSA was worse after LAUP.

Only limited data are available regarding the operative risks and side effects of LAUP. Most reports indicate severe postoperative pain for $1-3$ weeks. Carenfelt ${ }^{23}$ reported that $27 \%$ of patients developed slight or moderate scar fibrosis after LAUP compared with $14 \%$ of patients after UPPP. Two patients who underwent LAUP developed velopharyngeal stenosis that was made worse by reoperation with UPPP. Velopharyngeal insufficiency was apparently infrequent and short lived. Since LAUP usually involves a less radical resection of pharyngeal tissue than UPPP, there is the potential for early postoperative upper airway obstruction secondary to oedema. This issue was addressed in a study by Terris and colleagues ${ }^{38}$ who examined the effects of LAUP on sleep disordered breathing and upper airway size in seven patients. Polysomnography, magnetic resonance imaging, and videoendoscopy of the upper airway were performed in each patient before and 48-72 
hours after LAUP. The AI increased from 3.3 (3.5)/hour to $14.8(10.9)$ /hour $(\mathrm{p}<0.03)$ and the RDI increased from 11.3 (10.9)/hour to 21.7 (9.9)/hour (not significant). The cross-sectional area of the upper airway decreased by $48 \%$ $(p<0.01)$. The authors concluded that LAUP may temporarily worsen OSA and recommended perioperative use of nasal CPAP in patients with more than mild OSA. It should be noted, however, that the severity of OSA is not predictive of the risk of postoperative airway complications following corrective upper airway surgery. ${ }^{46}$

The long term efficacy of LAUP has not been assessed to date. Furthermore, the long term implications of eliminating the snoring noise in patients with OSA is unclear. Since it is likely that many patients currently undergoing LAUP for snoring have undiagnosed OSA, the reduction or elimination of their snoring may further delay a complete diagnosis in these patients, potentially leading to increased morbidity and mortality. The impact of a failed LAUP on subsequent treatment modalities for OSA is unknown. There is concern, for instance, that a failed UPPP decreases the likelihood of subsequent successful nasal CPAP therapy. ${ }^{47}$ The effect of an unsuccessful LAUP on subsequent nasal CPAP therapy is unknown.

To summarise the limited data currently available, it appears that the subjective efficacy of LAUP for the relief of snoring, and the objective efficacy for the treatment of OSA, are no better than UPPP. Variations in surgical technique may actually predispose to an increased risk of postoperative velopharyngeal stenosis compared with UPPP. The less extensive resection of pharyngeal tissue compared with UPPP may predispose to early postoperative upper airway obstruction following LAUP, with the potential for significant morbidity and even mortality. The author is aware of one instance of an unexplained postoperative death following LAUP which is currently the subject of litigation. Approximately $20-25 \%$ of patients with OSA who undergo LAUP are worse after treatment when follow up sleep monitoring is performed within six months of surgery. The long term efficacy of LAUP is unknown. There are no data available concerning whether LAUP can convert simple snoring into significant OSA, although clearly the potential for such an outcome exists. Many questions regarding LAUP remain unanswered.

Is it still possible to assess this new surgical procedure objectively and to influence its subsequent utilisation, or is it already too late? The more sceptical appraisal of LAUP that is apparent in recent articles ${ }^{3840}$ and the recognition of the methodological deficiencies in the literature on upper airway surgery for $\mathrm{OSA}^{28}$ give some cause for hope in this regard. Furthermore, most of the articles on LAUP reviewed for this editorial come from academic institutions where undoubtedly there exists expertise in the design of clinical trials. I believe there is an obligation on physicians with expertise in study methodology, who are involved in the care of patients with sleep disordered breathing, to engage in collaborative research with otolaryngologists to address better the many important questions that need to be answered regarding LAUP. These answers can only be obtained by conducting careful research based on sound methodology.

Among the many questions that need to be addressed are the following. What is the long term efficacy of LAUP for the treatment of snoring and OSA? How does LAUP work? Can preoperative assessment by clinical examination, upper airway imaging, or physiological assessment be used to select the patients most likely to obtain a good response to LAUP? What are the contraindications and complications of this procedure? Does unsuccessful LAUP interfere with subsequent treatment for OSA such as nasal CPAP? Can LAUP be usefully combined with other treatment modalities such as oral appliance therapy to enhance efficacy? Until the answers to these and other questions are known, a cautious approach to LAUP is warranted. Readers are referred to the practice parameters for the use of LAUP published recently by the American Sleep Disorders Association ${ }^{1}$ which contain specific recommendations that are summarised here. Until adequate peer reviewed objective data are available, LAUP should not be used to treat sleep related breathing disorders including OSA. Adequate preoperative evaluation, including an objective measure of respiration during sleep, should be performed on patients undergoing LAUP for snoring. Patients should be informed that the risks, benefits, and complications of LAUP have not been established. Those who undergo LAUP for snoring may incur the risk of a delay in diagnosing OSA and should be followed postoperatively. To this I would add the recommendation that a postoperative measure of respiration during sleep be obtained, since an unsuccessful LAUP could convert simple snoring into obstructive apnoea. Otolaryngologists need to be aware of the risk of perioperative upper airway obstruction following LAUP and take appropriate measures to avoid this potentially lethal complication.

Current treatment for snoring and OSA is far from satisfactory and there is no room for complacency. Corrective upper airway surgery, including LAUP, undoubtedly has a part to play in the treatment of these disorders. The challenge remains to delineate this role as precisely and as expeditiously as possible.

Dr Ryan is a British Columbia Health Research Foundation Scholar.

Division of Respiratory Medicine

C FRANCIS RYAN

University of British Columbia,

Vancouver Hospital and Health Sciences Centre,

2775 Heather Street,

Vancouver, BC V5Z 375,

Canada

1 Standards of Practice Committee of the American Sleep Disorders Association. Practice parameters for the use of laser-assisted uvulopalatoplasty. Sleep 1994;17:744-8.

2 Lugaresi E, Cirignotta F, Coccagna G, Piana C. Some epidemiological data on snoring and cardiopulmonary disturbances. Sleep 1980;3:221-4.

3 Partinen M, Palomaki H. Snoring and cerebral infarction. Lancet 1985;ii: 1325-6.

4 Koskeunou M, Kaprio J, Telakivi T, Partinen M, Heikkila K, Sarna S. Snoring as a risk factor for ischemic heart disease and stroke in men $B M \mathcal{F} 1987 ; 294: 16-9$.

5 Lugaresi E, Partinen M. Prevalence of snoring. In: Saunders NA, Sullivan CE, eds. Sleep and breathing: Lung Biology in Health and Disease. New York: Marcel Dekker, 1994: 337-61.

6 Remmers JE. Anatomy and physiology of upper airway obstruction. In: Kryger MH, Roth T, Dement WC, eds. Principles and practice of sleep medicine. Philadelphia: Saunders, 1989: 525-36.

7 Stradling JR, Crosby JH. Predictors and prevalence of obstructive sleep apnea and snoring in 1001 middle-aged men. Thorax 1991;46:85-90.

8 Young T, Palta M, Dempsey J, Skatrud J, Weber S, Badr S. The occurrence of sleep-disordered breathing among middle-aged adults. $N$ Engl f Med 1993;328:1230-5

9 Guilleminault C. Clinical features and evaluation of obstructive sleep apnea. In: Kryger MH, Roth T, Dement WC, eds. Principles and practice of sleep medicine. Philadelphia: Saunders, 1994: 667-77.

10 Borowiecki B, Pollak CP, Weitzman, Rakoff S, Imperato J. Fiberoptic study of pharyngeal airway during sleep in patients with hypersomnia obstructive sleep apnea syndrome. Laryngoscope 1978;88:1310-3

11 Suratt PM, Dee P, Atkinson RL, Armstrong, P, Wilhoit SC. Fluoroscopic and computed tomographic features of the pharyngeal airway in obstructive sleep apnea. Am Rev Respir Dis 1983;127:487-92.

12 Stein MG, Gamsu G, deGeer G, Golden JA, Crumley RL, Webb WR. Cine CT in obstructive sleep apnea. Am f Roentgenol 1987;148:1069-74.

13 Croft CB, Pringle M. Sleep nasendoscopy: a technique of assessment in snoring and obstructive sleep apnea. Clin Otolaryngol 1991;16:504-9.

14 Horner RL, Shea SA, McIvor J, Guz A. Pharyngeal size and shape during wakefulness and sleep in patients with obstructive sleep apnea. $Q \mathcal{F} M e d$ 1989;72:719-35.

15 Ryan CF, Lowe AA, Li D, Fleetham JA. Three-dimensional upper airway computed tomography in obstructive sleep apnea. Am Rev Respir Dis 1991;144:428-32.

16 Launois SH, Feroah TR, Campbell WN, Issa FG, Morrison D, Whitelaw WA, et al. Site of pharyngeal narrowing predicts outcome of surgery for obstructive sleep apnea. Am Rev Respir Dis 1993;147:182-9.

17 Ryan, CF, Love LL. Mechanical properties of the velopharynx in obese patients with obstructive sleep apnea. Am f Respir Crit Care Med 1996; 154:806-12

18 Sullivan CE, Issa FG, Berthon-Jones, M, Eves L. Reversal of obstructive sleep apnea by continuous positive airway pressure applied through the
nares. Lancet $1981 ; \mathrm{i}: 862-5$. 
19 Ikematsu T. Study of snoring, 4th report: therapy. $\mathcal{F}$ Fpn Otol Rhinol Laryngol 1964;64:434-5.

20 Fujita S, Conway W, Zorick F, Roth T. Surgical correction of anatomic abnormalities in obstructive sleep apnea syndrome: uvulopalatopharyngoplasty. Otolaryngol Head Neck Surg 1981;89:923-34.

21 Sher AE, Schectman KB, Piccirillo JF. The efficacy of surgical modifications of the upper airway in adults with obstructive sleep apnea syndrome. Sleep 1996;19:156-77.

22 Kamami YV. Laser $\mathrm{CO}_{2}$ for snoring - preliminary results. Acta Otorhinolaryngol Belg 1990;44:451-6.

23 Carenfelt C. Laser uvulopalatoplasty in treatment of habitual snoring. Ann Otol Rhinol Laryngol 1991;100:451-4.

24 Wennumo C, Olsson P, Flisberg K, Paulsson B, Luttrup S. Treatment of snoring - with and without carbon dioxide laser. Acta Otolaryngol (Stockh) 1992;492:152-5

25 Kamami YV. Outpatient treatment of sleep apnea syndrome with $\mathrm{CO}_{2}$ laser: laser-assisted UPPP. F Otolaryngol 1994;23:395-8.

26 Snider GL. Health-care technology assessment of surgical procedures. the case of reduction pneumoplasty for emphysema. Am 7 Respir Crit Care Med 1996;153:1208-13.

27 Bante DH, Luce BR. Health care technology and its assessment: an international perspective. New York: Oxford University Press, 1993.

28 Schechtman KB, Sher AE, Piccirillo JF. Methodological and statistical problems in sleep apnea research. the literature on uvulopalatopharyngoplasty. Sleep 1995;18:659-66.

29 Ellis PDM, Williams JEF, Shneerson JM. Surgical relief of snoring due to palatal flutter: a preliminary report. Ann R Coll Surg Engl 1993;75:286-90.

30 Ellis PDM. Laser palatoplasty for snoring due to palatal flutter: a further report. Clin Otolaryngol 1994;19:350-1.

31 Krespi YP, Pearlman SJ, Keidar A. Laser-assisted uvulo-palatoplasty for snoring. F Clin Otolaryngol 1994;23:328-34.

32 Kamami YV. Outpatient treatment of sleep apnea syndrome with $\mathrm{CO}_{2}$ laser, LAUP: laser-assisted UPPP results on 46 patients. 7 Clin Laser Med Surg 1994;12:215-9.

33 Morar P, Nandapalan V, Lesser THJ, Swift AC. Mucosal strip/uvulectomy by the $\mathrm{CO}_{2}$ laser as a method of treating simple snoring. Clin Otolaryngol 1995;20:308-11.
34 Blythe WR, Henrich DE, Pillsbury HC. Outpatient uvuloplasty: an in expensive single-staged procedure for the relief of symptomatic snoring. Otolaryngol Head Neck Surg 1995;113:1-4

35 Walker, RP, Geigg-Damberger MM, Gopalsami C, Totten MC. Laserassisted uvulopalatoplasty for snoring and obstructive sleep apnea: results in 170 patients. Laryngoscope 1995;105:938-42.

36 Zinder DJ, Postma GN. Outpatient cautery-assisted uvulopalatoplasty. Laryngoscope 1995;105:1256-7.

37 Mickelson SA. Laser-assisted uvulopalatoplasty for obstructive sleep apnea. Laryngoscope 1996;106:10-3.

38 Terris DJ, Clark AA, Norbash AM, Troell RJ. Characterization of postoperative edema following laser-assisted uvulopalatoplasty using MRI and polysomnography: implications for the outpatient treatment of obstructive sleep apnea syndrome. Laryngoscope 1996;106:124-8.

39 Wareing M, Mitchell D. Laser-assisted uvulopalatoplasty: an assessment of technique. 7 Laryngol Otol 1996;110:232-6.

40 Vaidya AM, Petruzzelli GJ, Walker RP, McGee D, Gopalsami C. Identifying obstructive sleep apnea in patients presenting for laser-assisted uvulopalatoplasty. Laryngoscope 1996;106:431-7.

41 Miljeteig H, Hateika S, Haight JS, Cole P, Hoffstein V. Subjective and objective assessment of uvulopalatopharyngoplasty for treatment of snorand asstructive sleep apnea. Am 7 Respir Crit Care Med 1994;150 $1286-90$.

42 Viner S, Szalai JP, Hoffstein V. Are history and physical examination a good screening test for sleep apnea? Ann Intern Med 1991;115:356-9.

43 Crocker BD, Olson LG, Saunders NA, Hensley MJ, McKeon JL, Allen $\mathrm{KM}$, et al. Estimation of the probability of disturbed breathing during sleep before a sleep study. Am Rev Respir Dis 1990;142:14-8.

44 Hoffstein V, Szalai JP. Predictive valve of clinical features in diagnosing obstructive sleep apnea. Sleep 1993;16:118-22.

45 Hillerdal G, Hetta J, Lindholm CE, Hultcrantz E, Boman G. Symptoms in heavy snorers with and without obstructive sleep apnea. Acta Otolaryngol in heavy snorers with and with

46 Esclamado RM, Glenn MG, McCulloch TM, Cummings CW. Perioperative complications and risk factors in the surgical treatment of obstructive complications and risk factors in the surgical treatm

47 Mortimore IL, Bradley PA, Murray JAM, Douglas NJ. Nasal CPAP therapy for sleep apnea may be compromised by uvulopalatopharyngoplasty. Am f Respir Crit Care Med 1996;153:A357. 